\title{
Numerical Model to Quantify the Influence of the Cellulosic Substrate on the Ignition Propensity Tests*
}

\author{
by \\ Pablo Guindos ${ }^{1}$, Christian Michel ${ }^{2}$, and Cindy Weichert ${ }^{3}$ \\ ${ }^{1}$ Fraunhofer Institut für Holzforschung, 38108 Braunschweig, Germany \\ ${ }^{2}$ HHP Nord/Ost Beratende Ingenieure GmbH, 38100 Braunschweig, Germany \\ ${ }^{3}$ Technische Universität Braunschweig, 38104 Braunschweig, Germany
}

\section{SUMMARY}

A numerical model based on the finite element method has been constructed to simulate the ignition propensity (IP) tests. The objective of this mathematical model was to quantify the influence of different characteristics of the cellulosic substrate on the results of the IP-tests. The creation and validation of the model included the following steps: (I) formulation of the model based on experimental thermodynamic characteristics of the cellulosic substrate; (ii) calibration of the model according to cone calorimeter tests; (iii) validation of the model through mass loss and temperature profiling during IP-testing. Once the model was validated, the influence of each isolated parameter of the cellulosic substrate was quantified via a parametric study. The results revealed that the substrate heat capacity, the cigarette temperature and the pyrolysis activation energy are the most influencing parameters on the thermodynamic response of the substrates, while other parameters like heat of the pyrolysis reaction, density and roughness of the substrate showed little influence. Also the results indicated that the thermodynamic mechanisms involved in the pyrolysis and combustion of the cellulosic substrate are complex and show low repeatability which might impair the reliability of the IP-tests. [Beitr. Tabakforsch. Int. 27 (2016) 102-112]

\section{RESUME}

Un modèle de calcul fondé sur la méthode des éléments finis a été bâti afin de simuler les essais de propension à l'inflammation (PI). L'objectif de ce modèle mathématique était la quantification de l'incidence des diverses caractéristiques du substrat cellulosique sur les résultats des essais de PI. Le montage et la validation du modèle ont suivi plusieurs étapes: (i) formulation du modèle sur la base des caractéristiques thermodynamiques expérimentales du substrat cellulosique; (ii) calibration du modèle grâce à des essais avec calorimètre à cône; (iii) validation du modèle par profilage de température et de perte de masse durant les essais de PI. Après la validation du modèle, l'incidence de chaque paramètre isolé du substrat cellulosique a été quantifiée par une étude paramétrique. Les résultats ont mis en lumière que la capacité calorifique du substrat, la température de la cigarette et l'énergie d'activation de la pyrolyse étaient les facteurs les plus déterminants de la réaction thermodynamique des substrats tandis que d'autres paramètres telles que la chaleur de la réaction pyrolytique, la densité et la rugosité du substrat ne présentaient qu'une faible incidence. Par conséquent, les résultats ont indiqué que les mécanismes thermodynamiques impliqués dans la pyrolyse et la combustion du substrat cellulosique sont complexes et présentent une faible répétabilité susceptible de compromettre la fiabilité des essais de faible propension à l'inflammation. [Beitr. Tabakforsch. Int. 27 (2016) 102-112] 


\section{ZUSAMMENFASSUNG}

Es wurde ein auf der Finite-Elemente-Methode basierendes Modell entwickelt, um Tests zur Beurteilung der Zündneigung (Ignition Propensity - IP) von Zigaretten zu simulieren. Ziel des mathematischen Modells war die Berechnung, welchen Einfluss die Charakteristika des auf Zellulose basierenden Substrates auf das Normprüfverfahren (IPTest) und die Testergebnisse haben. Der Aufbau und die Validierung des Modells erfolgten in drei Stufen: (i) Bestimmung der thermodynamischen Eigenschaften des auf Zellulose basierenden Substrates durch experimentelle Untersuchungen; (ii) Kalibrierung des Modells durch Versuche mit dem Cone-Calorimeter-Test; (iii) Validierung des Modells durch die Parameter Gewichtsverlust und Temperaturgradient während des IP-Tests.

Nach der Validierung des mathematischen Modells wurde der Einfluss jedes Parameters einzeln in einer Parameterstudie quantifiziert. Die Ergebnisse der Parameterstudie zeigen, dass die Wärmekapazität des Substrates, die Gluttemperatur der Zigarette und die erforderliche Aktivierungsenergie für die Pyrolysereaktion signifikante Einflussfaktoren für die thermodynamische Reaktion des Substrates sind. Doch haben die Reaktionsenthalpie der Pyrolysereaktion, die Rauheit und die Dichte des Substrates einen geringen Einfluss gezeigt. Die Ergebnisse zeigen zudem, dass die sehr komplex und heterogen ablaufenden thermodynamischen Prozesse die Pyrolyse- und Verbrennungsreaktion beeinflussen und so die Zuverlässigkeit des IP-Tests beeinträchtigen. [Beitr. Tabakforsch. Int. 27 (2016) 102-112]

\section{INTRODUCTION}

According to some sources (1), unattended cigarettes might be a potential risk of accidental fires. This potential risk has led to the prescription of the so-called Ignition Propensity (IP) test to assess, whether a specific cigarette might entail an accidental risk when left unattended. Because most furniture is typically fabricated with organic materials, it has been proposed to test such a potential risk by placing a cigarette on a cellulosic substrate and assessing, whether the cigarette self-extinguishes or not. Thus, the corresponding self-extinguishing capacity of each specific cigarette can be determined under a potentially risky scenario. In this context, the International Organization for Standardization has published the ISO 12863 IP-test (2) which prescribes the utilization of the commercial Whatman ${ }^{\circledR}$ Paper No. 2 as standard cellulosic substrate (filter paper) and defines the testing protocol. However, the results of this test show low repeatability, and also the testing itself is rather expensive. In addition, it is so far unclear what the most influencing properties of the substrate on the performance of the IP-test are, and therefore it is not possible to develop any alternative substrate. Hence, the main objective of this primary investigation was to find the most influencing parameters of the substrate. Previous investigations attempted to evaluate the performance of the IP-test by statistical analysis (3-6) but the complex nature of the thermodynamic process penalizes the effect of stochastic approaches. Therefore, the primary objective of the present investigation was to evaluate the influence of the cellulosic substrate on a deterministic basis, i.e., by modelling the main physical and chemical phenomena.

Although previous authors have constructed mechanistic models to simulate the thermodynamic behaviour of cigarettes (7-14), and some investigations have been conducted to model the behaviour of cigarettes lying on textile fabrics (15-18), there is little or no research on the modelling of the cigarette placed on multiple paper layers, as it occurs in the IP-tests. Therefore, this investigation was specifically focussed on the modelling of the thermodynamic behaviour of the cellulosic substrate during the performance of the tests. Such thermodynamical analysis can be useful to understand the main influencing parameters of the substrate, but it should be noted however, that the model does not intend to explain the result (self-extinguishment of the cigarette) of the IP-test itself.

\section{EXPERIMENTAL CHARACTERIZATION}

Prior to the elaboration of the mathematical model, the main physical characteristics of the substrate (Whatman ${ }^{\mathbb{B}}$ Paper No. 2) were experimentally measured. The number of samples, corresponding standards $(2,19-25)$ and experimental results are detailed in Table 1. The objective of these measurements was to support the mathematical model with experimental data, i.e., the use of the measured values as input parameters for the model when relevant.

Table 1. Experimental measurements of the cellulosic substrate prior to the elaboration of the mathematical model.

\begin{tabular}{|c|c|c|c|c|c|}
\hline Test & Standard / Testing apparatus (reference) & $\mathrm{N}$ & \multicolumn{3}{|c|}{ Mean $( \pm S D)$} \\
\hline Moisture content (\%) & ISO 287 (18) & 20 & 6.360 & \pm & 0.078 \\
\hline Thickness (mm) & ISO 534 (19) & 20 & 0.191 & \pm & 0.007 \\
\hline Density $\left(\mathrm{g} / \mathrm{cm}^{3}\right)$ & ISO 534 (19) & 20 & 0.525 & \pm & 0.021 \\
\hline Specific volume $\left(\mathrm{m}^{3} / \mathrm{g}\right)$ & ISO 534 (19) & 20 & 1.909 & \pm & 0.078 \\
\hline Grammage $\left(\mathrm{g} / \mathrm{m}^{2}\right)$ & ISO $536(20)$ & 20 & 99.915 & \pm & 0.92 \\
\hline Permeance $(\mu \mathrm{m} / \mathrm{Pa} \cdot \mathrm{s})$ & ISO 5636-3 (21) & 10 & 25.7 & \pm & 1.14 \\
\hline $\begin{array}{l}\text { Roughness }(\mathrm{mL} / \mathrm{min}) \text { at the upper }(\mathrm{A}) \\
\text { and lower sides }(\mathrm{B})\end{array}$ & ISO $8791-2(22)$ & 10 & $\begin{array}{l}A=1685 \\
B=1165\end{array}$ & $\begin{array}{l} \pm \\
\pm\end{array}$ & $\begin{array}{l}88.4 \\
41.2\end{array}$ \\
\hline Gross heat of combustion (kJ/kg) & ISO 1716 (23) & $1(500 \mathrm{~g})$ & \multicolumn{3}{|c|}{16,808} \\
\hline Net heat of combustion $(\mathrm{kJ} / \mathrm{kg})$ & ISO $1716(23)$ & $1(500 \mathrm{~g})$ & \multicolumn{3}{|c|}{15,432} \\
\hline Heat capacity $(\mathrm{J} / \mathrm{g} \cdot \mathrm{K})$ & DIN 53765 (24) & 5 & 1.17 & \pm & 0.03 \\
\hline
\end{tabular}




\section{NUMERICAL MODEL}

\section{Numerical approximation method}

The underlying physical and chemical principles occurring in the cellulosic substrate during IP-testing can be adequately described by means of conservation equations. More specifically, the heat transfer mechanisms can be described through an energy-conservation equation, while mass transfer can be considered by a momentum-conservation law. Such equations commonly take the form of partial differential equations (PDE), as they are defined in the context of continuum mechanics. Given the complexity of the boundary conditions of the problem, i.e., the sophisticated heat transfer mechanism between cigarette and substrates, the exact resolution of the corresponding PDEs by analytical methods is unfeasible. Therefore, a numerical approximation method is required for the calculation of the solutions of the PDEs. This investigation has considered the finite element method because it is a highly developed numerical approximation method (26) capable to handle complex boundary conditions.

Particularly, the mathematical model was constructed in the commercial Software COMSOL Multiphysics ${ }^{\circledR}$ (COMSOL Group, Stockholm, Sweden).

\section{Governing equations}

The essential heat transfer mechanisms involved on the IPtest are illustrated in Figure 1. In view of the substrate, the cigarette acts like a heat source which moves at a certain velocity. Because the cigarette contacts the substrate only along a thin line, most of the heat transferred from the cigarette to the substrate occurs by radiation and convection. In addition, as presented subsequently, the used convective heat transfer coefficients already account for all the conduction losses according to measurements (15), thus the conduction is not to be considered in this model as a boundary condition. The heated substrate also releases heat to the ambient environment via convection and radiation. Although the internal heat transfer mechanism of organic fibrous materials is complex at the microscopic scale, where radiation and convection mechanisms among fibres take place, it can be adequately described at the observation scale by means of effective heat conduction coefficients (27). Also the thin air film in-between the substrate can be modelled at the macroscopic scale assuming a thin thermally resistive layer which insulates the heat conduction through the different layers (28).

According to KASHIWAGI and NAMBU (29), cellulosic substrate shows three different reactions during thermal oxidative degradation. The first is the pyrolysis reaction yielding to the chemical degradation of paper. The second concerns the oxidation of the released gases, which only takes place in case of flaming combustion. The last involves the oxidation of the char, which is quasi negligible in terms or reaction rates in comparison to the pyrolysis reaction (29). As the present investigation does not concern flaming combustion, it is assumed that only the pyrolysis reaction might have a significant influence on the heat balance of the system. In addition to energetic aspects, pyrolysis degradation also yields the transformation of

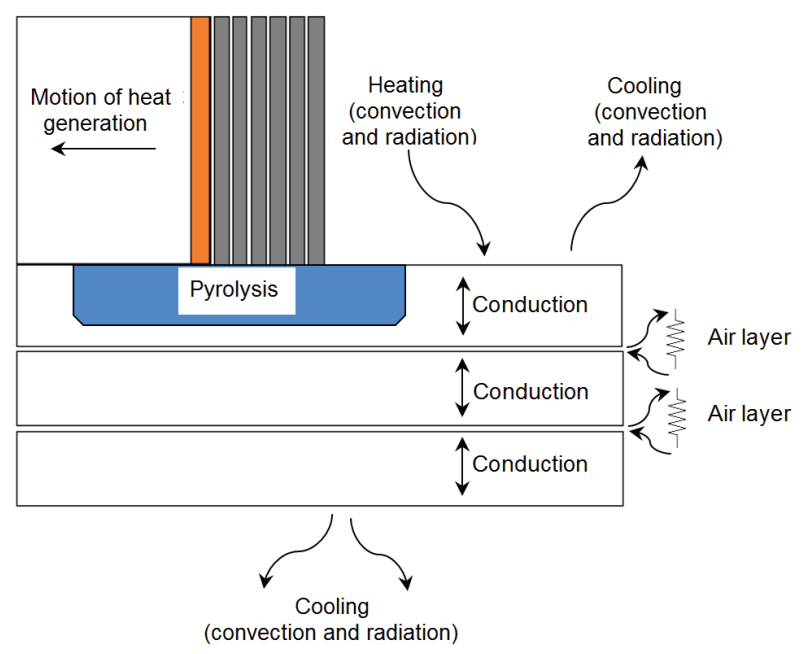

Figure 1. Essential thermal mechanisms during IP-testing. The schematic illustrates the side view of the top of a glowing cigarette lying on three filter substrates.

paper into gas and char, whose thermal properties vary significantly from those of the filter substrate (30). Accordingly, the dynamic energy balance of the filter paper during IP-testing was calculated as

$$
\rho c_{p} \frac{\partial T}{\partial t}=-\nabla\left(\lambda_{e f f} \nabla T\right)+Q
$$

where $\rho, c_{p}$ and $\lambda_{\text {eff }}$ are the density, heat capacity at constant pressure and effective thermal conductivity of the substrate, respectively. $T$ is the temperature, $t$ is the time, $Q$ is the heat of the pyrolysis reaction and $\nabla$ is the nabla operator, i.e., an operator that describes the spatial variation

$\nabla=\left(\frac{\partial}{\partial x}, \frac{\partial}{\partial y}, \frac{\partial}{\partial z}\right)$

Mass transfer in porous cellulosic materials subjected to steep thermal variations is typically described by a momentum conservation equation which is derived from the Darcy's law (30). In the present case however, the thinness of the substrate layers (ca. $0.19 \mathrm{~mm}$ ) relatively to the overall diameter size (ca. $125 \mathrm{~mm}$ ) drastically diminishes the significance of warming gases in the energy equation [Eq.1]. In this case it is therefore more practical to consider an effective thermal conductivity describing the combined heating mechanism through the substrate (heat conduction, and pore convection and radiation). Thus, the significance of mass balance equation consists of calculating the yield products, as the thermal properties of the char differ from those of the substrate. The mass balance is hence

$$
\frac{\partial c}{\partial t}=R_{p a p}
$$

where $c$ is the molar concentration of substrate (density divided by molar mass of cellulose in $\mathrm{mol} / \mathrm{m}^{3}$ ) and $R_{p a p}$ is 
the degradation rate of substrate concentration during the pyrolysis reaction. According to (29), the pyrolysis reaction of cellulosic substrate can be adequately described by an Arrhenius equation such that the reaction rate of the pyrolysis $\left(k_{p y r}\right)$ is computed as

$k_{p y r}=A e^{-E_{a} / R T}$

where $A$ is the preexponential factor, and $E_{a}$ is the activation energy. According to (29) $A$ is $1.2 \cdot 10^{19} \mathrm{~min}^{-1}$. The value of $E_{a}$ was taken in this research as $190 \mathrm{~kJ} / \mathrm{mol}$. This value was obtained after calibrating the model via cone calorimeter test (see subsequent sections) and is close to values measured by other authors (29). The measured fraction of char yield during pyrolysis was taken as $\alpha=20 \%$ (29). Thus, the substrate degradation $\left(R_{\text {pap }}\right)$, gas yield $\left(R_{g}\right)$ and char yield $\left(R_{c h}\right)$ rates can be calculated according to the reaction rate of the pyrolysis as

$$
\begin{aligned}
& R_{\text {pap }}=\frac{\partial c}{\partial t}=-k_{\text {pyr }} \\
& R_{c h}=\frac{\partial c_{c h}}{\partial t}=(1-\alpha) \cdot k_{p y r} \cdot c \\
& R_{g}=\frac{\partial c_{g a s}}{\partial t}=\alpha \cdot k_{p y r} \cdot c
\end{aligned}
$$

where $c_{c h}$ and $c_{\text {gas }}$ are the species concentrations of char and gas, and $\alpha$ is the measured fraction of char yield during pyrolysis, taking as $20 \%$ according to (29). The energy of the pyrolysis reaction $(Q)$ is computed according to the corresponding heat of the pyrolysis reaction $(\Delta H)$ as:

$$
Q=R \cdot \Delta H
$$

The heat of the reaction $\Delta H$ was taken as $300 \mathrm{~J} / \mathrm{g}$. This value was also obtained by best fit with cone calorimeter tests and is similar to values reported by other authors (29). The thermal properties of the substrate were modified during pyrolysis as follows: $c_{p}$ varied from $1100 \mathrm{~J} / \mathrm{kg} \cdot \mathrm{K}$ (30) to 1170 (measured value) and $\lambda_{\text {eff }}$ varied from $0.05 \mathrm{~W} / \mathrm{m} \cdot \mathrm{K}(30)$ to $0.104 \mathrm{~W} / \mathrm{m} \cdot \mathrm{K}(30)$.

\section{Boundary conditions}

The net heat absorbed by the cellulosic substrate $\left(\varphi_{n}\right)$ consists of the difference between the heat released from the cigarette to the filter substrate $\left(\varphi_{\text {cig }}\right)$, and the heat released from the filter substrate to the ambient environment $\left(\varphi_{a m b}\right)$

$$
\varphi_{n}=\varphi_{c i g}-\varphi_{a m b}
$$

According to the experimental set up (2), only the bottom and the top surface of the cellulosic substrate exchange heat with the ambient environment and cigarette. The net heat at the top $\left(\varphi_{n, t o p}\right)$ results from the balance between heat transferred from the cigarette by convection $\left(\varphi_{\text {cig,c }}\right)$ and radiation $\left(\varphi_{c i g, r}\right)$ and heat released to the ambient by convection $\left(\varphi_{a m b, c}\right)$ and radiation $\left(\varphi_{a m b, r}\right)$

$\varphi_{n, t o p}=\varphi_{c i g, c}+\varphi_{c i g, r}-\varphi_{a m b, c}-\varphi_{a m b, r}$

The heat convection of the cigarette into the substrate can be calculated as

$$
\varphi_{c i g, c}=\Omega \cdot h_{c}\left[T_{c i g}-T\right]
$$

where $T_{c i g}$ and $T$ are the temperatures of the cigarette and substrate, respectively, $h_{c}$ is the heat transfer coefficient between cigarette and substrate and $\Omega$ is a view factor, i.e., a dimensionless factor that scales the heat release along the direction transverse to the cigarette, being maximum at the contact line and approaching zero at a distance of about $10 \mathrm{~mm}$, see illustration in Figure 2a. According to (15), $h_{c}$ can be taken as $71 \mathrm{~W} / \mathrm{m}^{2} \cdot \mathrm{K}$ and $\Omega$

$\Omega \approx e^{-y^{2} / s_{y}^{2}}$

where $y$ is the perpendicular distance to the glowing direction of the cigarette, and $s_{y}$ is the variance of the view function estimated as 0.8 times the radius of the cigarette for standard cigarettes this results on a view factor similar to a Gauss function yielding to negligible heat exchange at a perpendicular distance beyond $10 \mathrm{~mm}$, see Figure 2. The heat irradiated by the cigarette was computed as

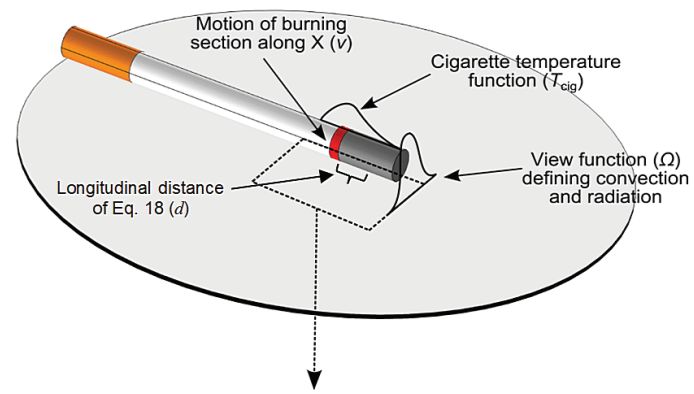

Figure 2 (a). Physical geometry of the glowing cigarette lying on a stack of 10 substrates during IP-test. The profile of the longitudinal cigarette temperature $T_{\text {cig }}$ and view function $\Omega$ is also illustrated.

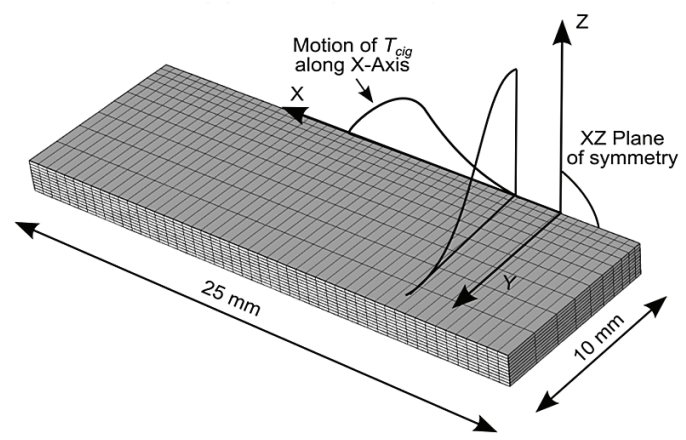

Figure 2 (b). Corresponding geometry of the mathematical model including the view and temperature functions and the finite element mesh. Note that the mesh is greatly enlarged in this figure to enhance the visibility. 


$$
\varphi_{c i g, r}=\varepsilon_{e f} \delta \Omega\left[T_{c i g}{ }^{4}-T_{a m b}{ }^{4}\right]
$$

where $T_{a m b}$ is the ambient temperature, $\delta$ is the StefanBoltzmann constant, and $\varepsilon_{e f}$ is the effective emissivity

$$
\varepsilon_{e f}=\frac{\varepsilon_{c i g} \varepsilon_{p a p}}{1-\left[\left(1-\varepsilon_{p a p}\right)\left(1-\varepsilon_{c i g}\right)\right]}
$$

Both the emissivity of substrate $\left(\varepsilon_{\text {pap }}\right)$ and cigarette $\left(\varepsilon_{\text {cig }}\right)$ were taken as 0.9 (32). According to (15), the convection of heat to the ambient can be calculated as

$$
\varphi_{a m b, c}=h_{p}\left[T_{a m b}-T\right]
$$

with

$$
h_{p}=h_{0}+\Delta h e^{-y^{2} / s_{y}^{2}}
$$

where $h_{0}$ is the reference heat transfer coefficient from the substrate to the ambient, taken as $10 \mathrm{~W} / \mathrm{m}^{2} \mathrm{~K}$ according to (15) and $\Delta h$ is the difference between $h_{c}$ and $h_{0}$, i.e., $61 \mathrm{~W} / \mathrm{m}^{2} \mathrm{~K}$. The heat irradiated from the paper to the ambient is

$$
\varphi_{a m b, r}=\left[\varepsilon_{e f} \Omega \varepsilon_{p a p}(1-\Omega)\right] \delta\left(T_{a m b}{ }^{4}-T^{4}\right)
$$

The net heat exchanged at the bottom surface $\left(\varphi_{n, b o t}\right)$ was calculated accounting for the heat released to the ambient by convection $\left(\varphi_{c, b o t}\right)$ and radiation $\left(\varphi_{r, b o t}\right)$

$$
\varphi_{n, b o t}=-\varphi_{c, b o t}-\varphi_{r, b o t}
$$

where

$$
\varphi_{c, b o t}=h_{0}\left[T_{a m b}-T\right]
$$

and

$$
\varphi_{r, b o t}=\varepsilon_{p a p} \delta\left[T_{a m b}^{4}-T^{4}\right]
$$

As proposed by other authors (15), the cigarette was not explicitly modelled but it was accounted for as a constant heat source moving at a certain velocity. The temperature of the cigarette $\left(T_{c i g}\right)$ was taken as the plain average temperature of the solid and gaseous phases reported by BAKER (33), except that the peak temperature was considered as $600{ }^{\circ} \mathrm{C}$ according to (15). Such plain average is considered a reasonable approximation as the temperatures of both phases are relatively similar at the contact line. The resulting temperature distribution was adjusted with the following polynomial function $\left(R^{2}=0.97\right)$

$$
T_{\text {cig }}=-2 \cdot 10^{9} \cdot d^{3}-3 \cdot 10^{7} \cdot d^{2}-75513 \cdot d+788
$$

where $T_{\text {cig }}$ is the temperature of the cigarette in Kelvin and $d$ is the longitudinal distance behind the coal to the burning section in meters, see an illustration of $T_{\text {cig }}$ in Figure 2. The model was created such that the cigarette was aligned with the $X$-axis and burned at a constant velocity $(v)$. Thus, the polynomial function describing the temperature of the cigarette during the IP-test becomes

$$
\begin{aligned}
T_{\text {cig }}= & -2 \cdot 10^{9}(x-v t)^{3}-3 \cdot 10^{7}(x-v t)^{2} \\
& -75513(x-v t)+788
\end{aligned}
$$

where $x$ is the longitudinal distance in meters traveled by the burning section and $t$ is time of the test in seconds. The velocity was measured in the tests as $0.053 \mathrm{~mm} / \mathrm{s}$.

The thin air film in-between substrate layers was modelled assuming a thin thermally resistive layer (28). The heat flux transferred from the lower side of one substrate layer to the upper side of the following substrate layer is calculated as

$$
-\mathbf{n}_{u}\left(-\lambda_{u} \nabla T_{u}\right)=\lambda_{l} \frac{\left(T_{d}-T_{u}\right)}{\delta_{l}}
$$

where $\boldsymbol{n}$ is the normal vector, $\lambda$ is the thermal conductivity, $T$ is the temperature, $t$ is the thickness and the subscripts $d$, $u$ and $l$ indicate that the properties are referred to the lower side, upper side and thin air layer, respectively. By interchanging the subscripts $d$ and $u$ in [Eq. 20], it is possible to compute the heat transferred from the upper side to the lower side. $t_{l}$ was calculated by adding the measured roughness of the substrate from upper $(1685 \mathrm{~mL} / \mathrm{min})$ and lower side $(1165 \mathrm{~mL} / \mathrm{min})$, and interpolating the result into length units according to (34), which resulted in $14 \mu \mathrm{m}$. $\lambda$ was calculated as the average value of the thermal conductivity of the substrate $(0.05 \mathrm{~W} / \mathrm{m} \cdot \mathrm{K})$ and the thermal conductivity of the air $\left(\lambda_{\text {air }}\right)$. The latter was assumed to be dependent upon temperature as proposed in (35):

$$
\begin{aligned}
\lambda_{\text {air }}= & -0.00228+1.15 \cdot 10^{-4} T \\
& -7.90 \cdot 10^{-8} T^{2}+4.12 \cdot 10^{-11} T^{3} \\
& -7.44 \cdot 10^{-15} T^{4}
\end{aligned}
$$

\section{Geometry and discretization}

The geometry of the model is illustrated in Figure 2. The $\mathrm{X}-, \mathrm{Y}-$ and $\mathrm{Z}$-directions corresponded to the glowing, perpendicular substrate distance and depth directions, respectively. The heat transfer is anisotropic - thus a 3D-model was mandatory. However, as the material properties, geometry and boundary conditions are symmetric in respect to plane $\mathrm{XZ}$, only half of the geometry was accounted for. In addition, as presented in subsequent sections, the heat transfer reaches a quasi-stable condition, i.e., the temperature profile in the substrate remains relatively constant after a certain time interval, and the heat transfer is negligible for $y>10 \mathrm{~mm}$. Therefore, only a stack of substrate of $25 \times 10 \mathrm{~mm}$ was modelled. The application of the time-dependent temperature of the cigarette as 
boundary condition [Eq. 19] permitted for considering the time-dependent heat released by the cigarette $\left(\varphi_{\text {cig,c }}\right.$ and $\left.\varphi_{\text {cig, },}\right)$. The finite element mesh was structured consisting on hexahedral elements with quadratic shape functions. The element size varied following a quadratic distribution as shown schematically in Figure 2. The number of finite elements was about 5,000 for a stack of 3 substrates, 20,000 for 10 substrates, and 30,000 for 15 substrates. The model computed a time interval of $150 \mathrm{sec}$ and the time discretization was automatically adapted from 0.01 to $2 \mathrm{sec}$.

\section{CALIBRATION}

The model was calibrated before being validated against experimental results of the IP-test. The calibration is a common practice for numerical models dealing with pyrolysis and combustion phenomena due to the complexity and uncertainty of experimental parameters (36). The experimental test used for model calibration was the cone calorimeter test which is wellknown for its accuracy. This test consists of placing a substrate under a highly controlled irradiating source (the cone) until it is completely combusted. The released gases are measured during the test which allows for calculating the energy released by the substrate.

The calibration tests were performed according to the corresponding standards (37) at the facility of the Materialprüfanstalt für das Bauwesen (MPA) of the TU Braunschweig, in Braunschweig, Germany. The model calibration was performed as conducted by STATLER (38). The objective of the calibration was to find out the optimal parameters of the model in order to reproduce the measured heat release rate $(H R R)$ of the filter paper. Three specimens were tested under the minimal possible radiation of $10 \mathrm{~kW} / \mathrm{m}^{2}$ and cone temperature of $533{ }^{\circ} \mathrm{C}$. The first consisted of 53 substrate layers (equivalent to a thickness of $10 \mathrm{~mm}$ ), the second included 10 substrate layers and the last one 3 substrate layers. However, the results of the latter were not used for model calibration because the ignition of the entire stack only lasted a few seconds.

The numerical model used for the calibration was as presented in the previous section, except that it was one-dimensional, because the heat in this test is only transferred in one dimension, and also a simple diffusion law of pyrolysis of the gases was included, so

$$
\frac{\partial c_{g}}{\partial t}=-\nabla\left(D \nabla c_{g}\right)+\sum R_{g}
$$

where $D$ is the diffusion coefficient of the pyrolysis gases through the substrate. Furthermore, a controlled radiation was used as boundary condition for the upper side instead of the cigarette and ambient induced boundary conditions. As presented in (38), an arbitrary Lagrangian-Eulerian formulation allowed for moving the mesh as the substrate stack was burnt, thus permitting the motion of the radiative boundary condition. The $H R R$ was then computed as

$$
H R R=\frac{\partial c_{g a s, n}}{\partial t} D \cdot H_{c}
$$

(a) 53 substrates

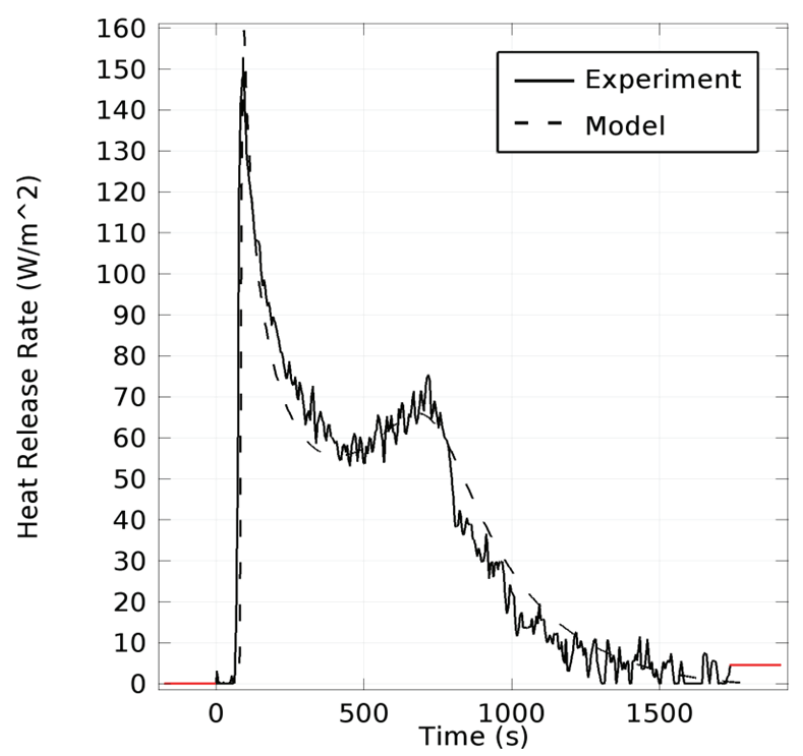

(b) 10 substrates

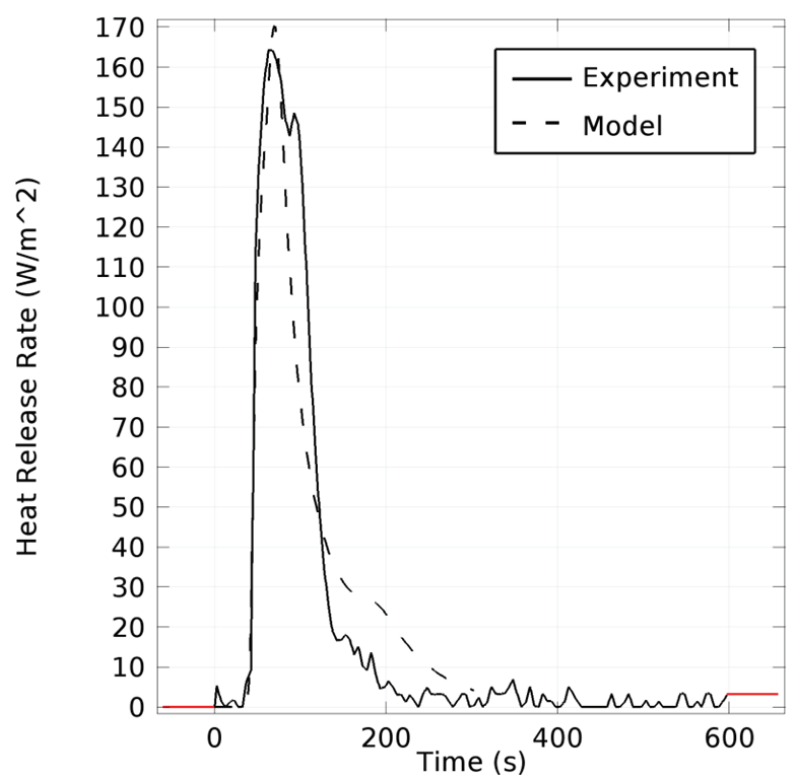

Figure 3. Model calibration via heat release rate (HRR) measured in the cone calorimeter test for the test specimens comprising (a) 53 and (b) 10 substrate layers.

where $c_{\text {gas, } n}$ is the mass flux of gases in the direction normal to the upper side and $H_{c}$ is the heat of the gases of the combustion reaction. $H_{c}$ was taken as $5700 \mathrm{~J} / \mathrm{g}$ according to (29). Because the typical diffusion coefficient of gases through the substrate, $D_{g, p}$, is different from that of the char, $D_{g, c h}(39,40)$, distinct values of $D$ were accounted for depending on the substrate concentration $(c)$.

The calibrated values consisted of the pyrolysis parameters $\Delta H$ and $E_{a}$, and the diffusion coefficients $D_{g, p}$ and $D_{g, c h}$. The comparison of the computed and measured $H R R$ is shown 
in Figure 3, and the corresponding values are presented in Table 2 . The resulting values of the calibration are similar to those reported in the literature, see Table 2.

Table 2. Results of model calibration.

\begin{tabular}{l|c|c|c}
\hline $\begin{array}{l}\text { Calibration } \\
\text { parameter }\end{array}$ & $\begin{array}{c}\text { Calibrated } \\
\text { value }\end{array}$ & $\begin{array}{c}\text { Values reported } \\
\text { in literature }\end{array}$ & Reference \\
\hline$D_{g, p}$ & $1 \cdot 10^{-5} \mathrm{~m}^{2} / \mathrm{s}$ & $5 \cdot 10^{-5} \mathrm{~m}^{2} / \mathrm{s}$ & $(38)$ \\
$D_{g, c h}$ & $0.7 \cdot 10^{-6} \mathrm{~m}^{2} / \mathrm{s}$ & $5.5 \cdot 10^{-6} \mathrm{~m}^{2} / \mathrm{s}$ & $(39)$ \\
$\Delta H$ & $300 \mathrm{~J} / \mathrm{g}$ & $570 \mathrm{~J} / \mathrm{g}$ & $(28)$ \\
$E_{a}$ & $190 \mathrm{~kJ} / \mathrm{mol}$ & $220 \mathrm{~kJ} / \mathrm{mol}$ & $(28)$ \\
\hline
\end{tabular}

\section{VALIDATION}

The numerical model was validated against a series of IPtests using the calibrated values of $\Delta H$ and $E_{a}$. The tests were conducted according to the corresponding standard (2). A first attempt to validate the model was to use type K thermocouples for measuring the temperature profile on the paper. This approach, however, was not feasible because the thermocouple unavoidably influenced either the heat transfer mechanism or the deformation of the substrate. Therefore, an infrared camera type FLIR ThermoCAM B20HS was used instead. This is a contactless measuring method which allows measuring the temperature profile of the upper side of the substrate, see Figure 4. The infrared camera needs to be calibrated at certain temperature ranges in order to measure the temperature gradients with high accuracy (up to $\pm 50 \mathrm{~m} \cdot \mathrm{K}$ ). During the experiments, the camera was calibrated for measuring the $130{ }^{\circ} \mathrm{C}$ isotherm because this isotherm was considered to be representative in view of the isotherms obtained from numerical simulation of the mathematical model.

The experiments revealed that the substrate reaches a quasistationary condition after a certain time interval, meaning that the temperature profile remains relatively constant up to the extinguishment stage. Such interval was for the case of 10 substrate layers about 2 min after the test started. As detailed in the next section, this aspect was also observed in the numerical model. This fact facilitated the validation process, and the numerical model verification was performed against the measurement of the $130^{\circ} \mathrm{C}$ isotherm during the quasi-stationary stage. The size of the isotherm was measured manually by image analysis. Furthermore, the burnt area at the upper side and the number of burnt substrate layers were also compared with the model, see Figure 4 and Table 3.

A series of 9 experiments was performed. The first 3 experiments included 3 substrate layers, experiments 4 through 6 contained 10 layers and tests 7 through 9 had 15 substrate layers. The linear burn rate of each cigarette was measured and included in the model. The results of the validation are presented in the Table 3. The error of the width of the combusted area on the paper was less than $1 \mathrm{~mm}(7.6 \%)$ in most cases. In general, the number of combusted substrate layers was correctly predicted. The errors on the size of the $130{ }^{\circ} \mathrm{C}$ isotherm were about $1.7 \mathrm{~mm}(11.7 \%)$. The errors seem reasonable according to the heterogeneity measured experimentally. (a) Measurement with infrared camera.

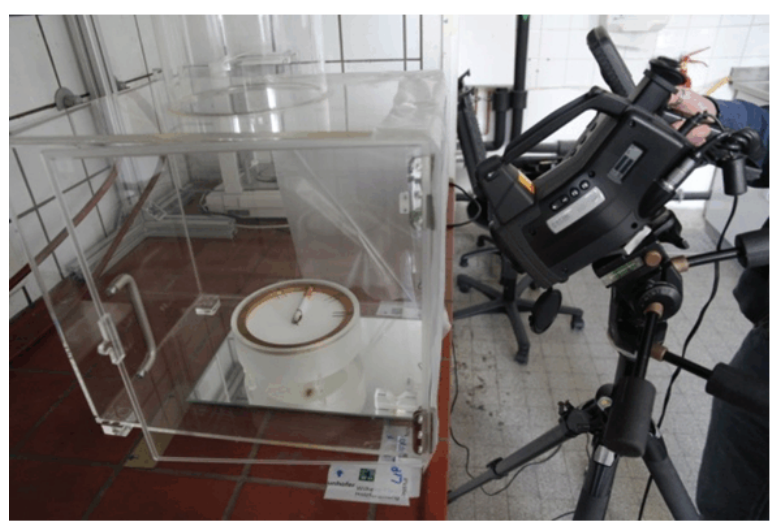

(b) Comparison of termperature profiles.
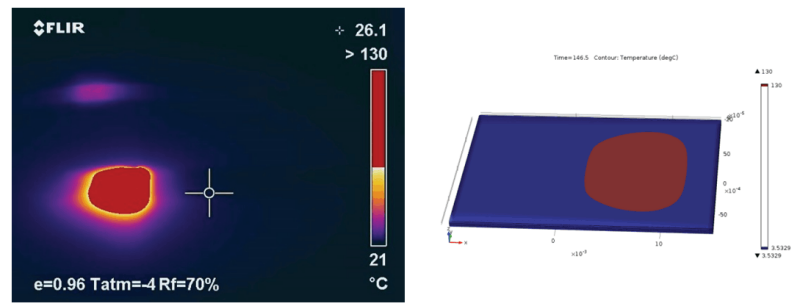

(c) Comparison of carbonized material.

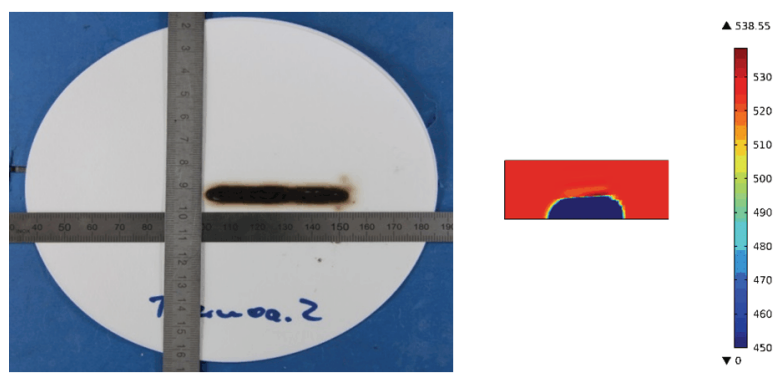

Figure 4. Numerical model validation including: (a) IP-test arrangement, (b) measurement of the temperature profiles with infrared camera (left) and comparison with numerical model (right), and (c) measurement of the carbonized area (left) and comparison with numerical model (right).

\section{RESULTS AND DISCUSSION}

The characteristic temperature and burnt paper profiles are illustrated in Figure 5. In order to quantify the influence of each parameter of the substrate on the IP-test, a parametric study was performed. Two results were selected in order to represent the overall influence of each isolated parameter. The first was the average heat flux absorbed at the upper side, and the second was the peak temperature at the lower side of the stack of substrates. These two parameters are considered to adequately represent the overall response of the test because the first one is a fair measure of the physical stimulus, and the latter is a suitable measurement of the overall response to that stimulus. 
Table 3. Results of model validation.

\begin{tabular}{|c|c|c|c|c|c|c|c|c|}
\hline \multirow{2}{*}{$\begin{array}{l}\text { No. of } \\
\text { substrates }\end{array}$} & \multirow{2}{*}{ Test No. } & \multirow{2}{*}{ Comment } & \multicolumn{2}{|c|}{$\begin{array}{l}\text { Width of burnt substrate } \\
(\mathrm{mm})\end{array}$} & \multicolumn{2}{|c|}{ No. of burnt substrates } & \multicolumn{2}{|c|}{$\begin{array}{c}\text { Size of the } 130^{\circ} \mathrm{C} \text { isotherm } \\
(\mathrm{mm})\end{array}$} \\
\hline & & & Experiment & Model & Experiment & Model & Experiment & Model \\
\hline \multirow{3}{*}{3} & 1 & - & 9 & 8.22 & 3 & 3 & 14.5 & 13.4 \\
\hline & 2 & - & 9 & 8.06 & 3 & 3 & 17.0 & 13.6 \\
\hline & 3 & - & 9 & 8.10 & 3 & 3 & 17.0 & 14.0 \\
\hline \multirow{3}{*}{10} & 4 & - & 8 & 7.40 & 6 & 6 & 15.7 & 14.1 \\
\hline & 5 & Short test ${ }^{a}$ & 6 & 7.40 & 5 & 6 & 15.7 & 14.1 \\
\hline & 6 & - & 8 & 7.64 & 6 & 6 & 16.4 & 14.4 \\
\hline \multirow{3}{*}{15} & 7 & No pyrolysis & - & - & - & - & - & - \\
\hline & 8 & - & 8 & 7.59 & 6 & 5 & 16.2 & 14.2 \\
\hline & 9 & - & 8 & 7.44 & 5 & 5 & 14.0 & 14.5 \\
\hline
\end{tabular}

a Self-extinguishing after $10 \mathrm{~mm}$

The summary of the analysed parameters, starting conditions, justification to each starting condition, studied range of parameters, and corresponding influences is presented in Table 4. The IP-test is a thermodynamic topic and therefore the influence of each parameter is not constant during the entire test - see an example of the influence of the heat capacity of the substrate in Figure 6. Thus, the parametric influences presented in Table 4 correspond to the maximum difference during a time period of $150 \mathrm{sec}$. As shown in Figure 6 this time interval is sufficiently long to capture the relevant influence of each parameter because the system reaches a quasi-stationary response in every case.

Note that the present model did not explicitly account for the glowing cigarette but that it considered a constant heat source, as did the previous investigations (15). It is, however, assumed that some parameters such as the substrate roughness might also have an influence on the heat released by the cigarette, i.e., some variables of the substrate also influence the cigarette which has been reported by other authors (41). Therefore, the presented results should be considered with caution as they exclusively indicate the influence of each parameter on the substrate.

As shown in Table 4, the most influencing parameters were the temperature of the cigarette, the heat capacity of the paper and the activation energy of the pyrolysis reaction. The average heat flux absorbed by the substrate and the temperature at the lower side increased by $33 \%$ and $10 \%$, respectively, when the temperature of the cigarette increased by $100{ }^{\circ} \mathrm{C}$. An increase of the heat capacity up to $2400 \mathrm{~J} / \mathrm{kg} \cdot \mathrm{K}$ increased the heat flux of the substrate by $10 \%$ and decreased the temperature on the lower side by $36 \%$. When reducing the activation energy of the pyrolysis reaction to $150 \mathrm{~kJ} / \mathrm{mol}$, the heat flux and temperature at the lower side decreased by $11 \%$ and $16 \%$, respectively.

The most important parameter determining the average heat flux absorbed by the substrate was the temperature of the cigarette. Furthermore a decrease of the pyrolysis activation energy significantly decreased the absorbed energy. If the heat capacity of the substrate is increased, then the energy absorbed by the substrate is significantly increased and this potentially can influence the results of the IP-test. Modifications of the thermal conductivity are also important; the substrate clearly absorbs more energy when increasing the thermal conductivity. The emission coefficient can also be a significant parameter, especially when increased. The most important aspect influencing the reaction of the substrate itself was the heat capacity. When increased, the temperature at the lower side of the substrate decreases drastically. The temperature of the cigarette is also very important which seems reasonable as it has a very strong influence on the heat released to the substrate. A decrease of the activation energy strongly influences the reaction of the substrate the pyrolysis is endothermic and a decrease in the activation energy leads to a significant increase of the reaction rate, therefore the temperature at the lower side is significantly reduced. Finally, a reduction of the thermal conductivity also causes a significant decrease of the substrate temperature.

\section{CONCLUSIONS}

The influence of the cellulosic substrate on the IP-test has been investigated from a deterministic point of view. This has been performed by developing a mathematical model that can simulate the thermodynamic mechanisms involved in the test. The model is based on a comprehensive experimental characterization, common physical properties measured by other authors and the physically measured response during cone calorimetry tests.

Comparisons of the model with actual IP experiments have indicated that the model can reasonably predict the response of the substrate during the aforementioned tests. Therefore, a parametric study has been conducted in order to quantify the influence of many parameters of the substrate. Results have revealed that the temperature of the cigarette, the heat capacity of the substrate and the activation energy of the pyrolysis reaction are the most influencing aspects. Thus, this investigation should contribute to a better understanding of the roles of the substrate characteristics and to a definition of the required specifications.

During this research it has also been found that the thermodynamic behaviour of the cellulosic substrate during the IPtest is a complex and variable problem which is influenced by a large number of parameters. Because the thermodynamics involved on a smouldering cigarette are also complex, the results of the ISO 12863 test are expected to show a low repeatability. 


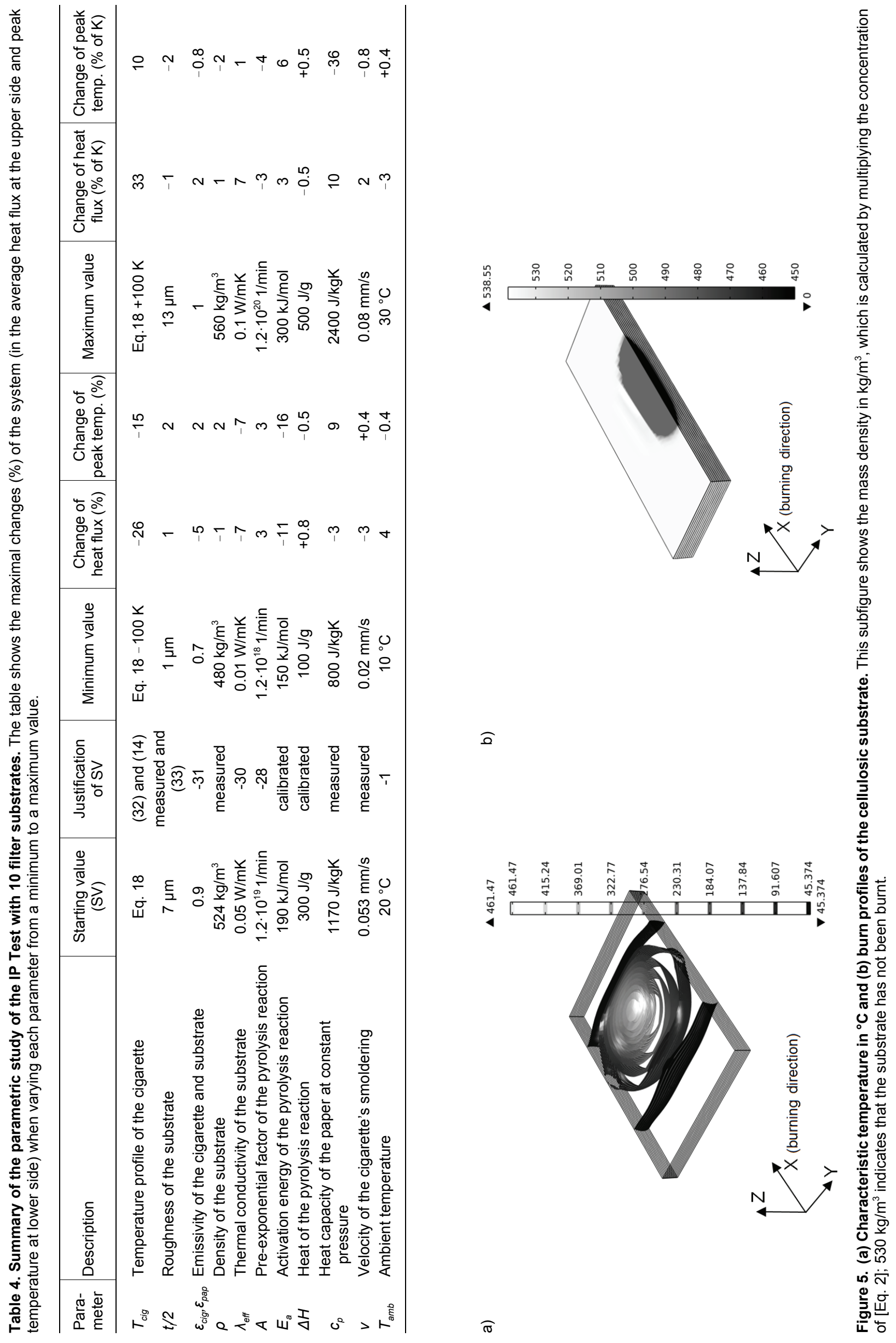



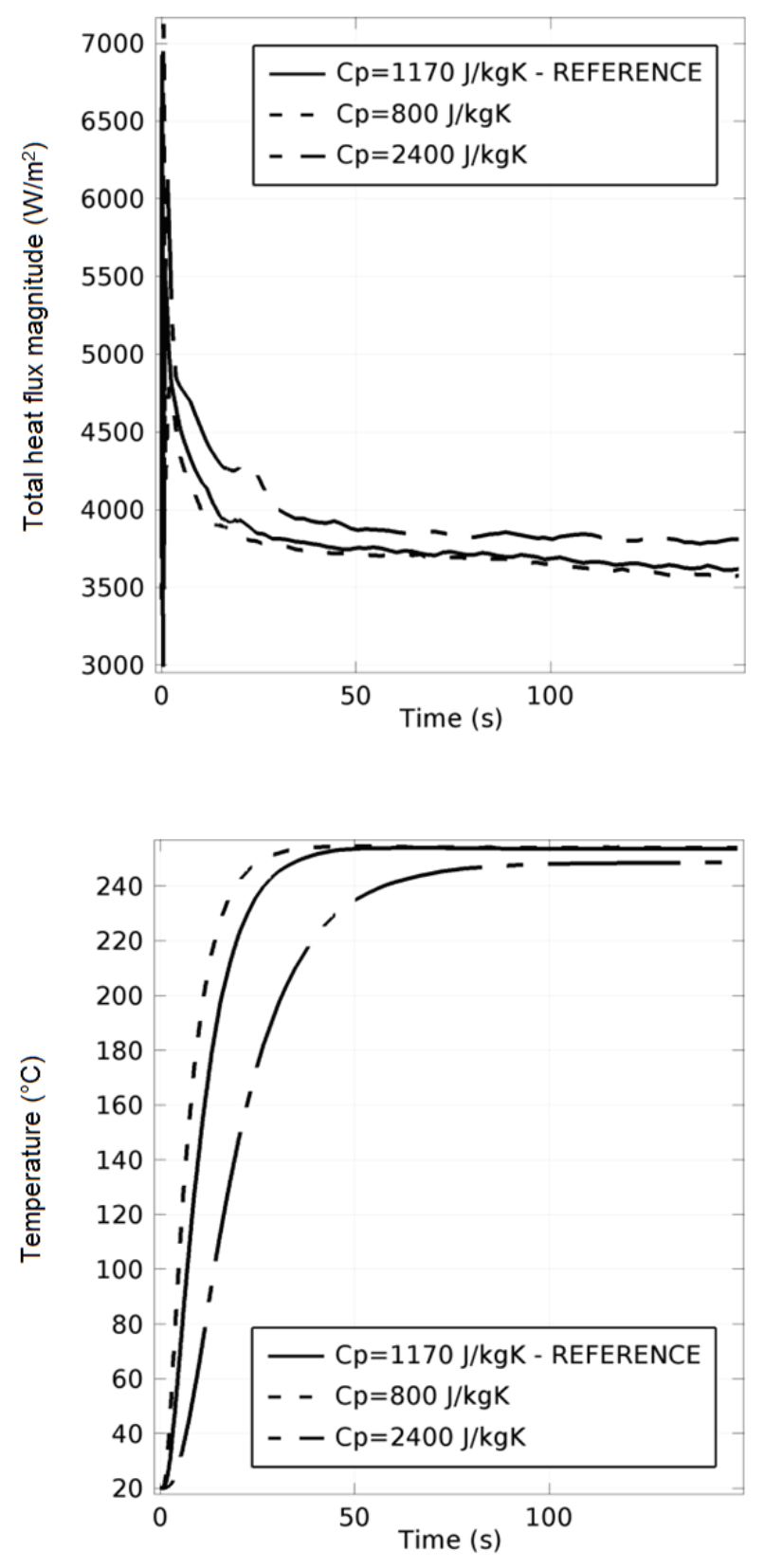

Figure 6. Influence of the heat capacity of the substrate on the IP-Test: (a) influence on the average heat on the upper side and (b) influence on the peak temperature on the lower side.

\section{ACKNOWLEDGMENTS}

The authors acknowledge the thorough constructive review by the reviewers that significantly improved the quality of the manuscript. ${ }^{1}$

This research was sponsored by Deutscher Zigarettenverband (DZV) and the authors are grateful for its support.

\section{REFERENCES}

1. Barillo, D.J., P.A. Brigham, D.A. Kayden, R.T. Heck, and A.T. McManus: The Fire-Safe Cigarette: A Burn Prevention Tool; J. Burn. Care. Rehabil. 21 (2000) 164-170.

2. International Organization of Standardization (ISO): International Standard 12863:2010. Standard Test Method for Assessing the Ignition Propensity of Cigarettes; ISO, Geneva, Switzerland, 2010.

3. Gann, R.G. and W.F. Guthrie: Robustness of Measuring the Ignition Strength of Cigarettes with ASTM Method E2187-02b; NIST Technical Note 1454, National Institute of Standards and Technology, Washington, DC, USA, 2003.

4. Su, J.Z., P. Leroux, and J.C. Latour: Cigarette Ignition Propensity Testing - First Series; Institute for Research in Construction, National Research Council, Canada 2003.

5. Gann, R.G.: Measuring the Ignition Propensity of Cigarettes; in: Proceedings of the $11^{\text {th }}$ Interflam Fire Science and Engineering Conference, London, UK, July 3-5, 2007, pp. 145-155.

6. Mehta, S.: Cigarette Ignition Risk Project; U.S. Consumer Product Safety Commission, Bethesda, MD, USA, 2012.

7. Eitzinger, B. and S. Pirker: Numerical Simulation of a Cigarette During Smoking; Beitr. Tabakforsch. Int. 21 (2005) 403-416. DOI: 10.2478/cttr-2013-0806

8. Eitzinger, B.: A Simulation Study of Self-Extinguishing Cigarettes; Beitr. Tabakforsch. Int. 22 (2006) 79-87. DOI: $10.2478 /$ cttr-2013-0819

9. Saidi, M.S., M.R. Hajaligol, and F. Rasouli: An Experimental and Numerical Analysis of Puff Hydrodynamics; Beitr. Tabakforsch. Int. 21 (2004) 157-166. DOI: $10.2478 /$ cttr-2013-0819

10. Chen, P.: A Mathematical Model of Cigarette Smoldering Process; Beitr. Tabakforsch. Int. 20 (2002) 265-271. DOI: $10.2478 /$ cttr-2013-0740

11. Muramatsu, M.: An Approach to Modeling a Burning Cigarette; Beitr. Tabakforsch. Int 21 (2005) 286-293. DOI: $10.2478 /$ cttr-2013-0795

12. Zheng, Y., J. Chipley, A. Dow, and C. Midgett: A Model for the Prediction of Tobacco Temperature and Oxygen Profiles in Warehouse Aging Process; Beitr. Tabakforsch. Int. 22 (2007) 358-364. DOI: 10.2478/cttr-2013-0842

13. Gaißer, H.: Fluiddynamik in der Cigarette und deren Einfluß auf den Zugwiderstand [Fluid Dynamics in the Cigarette and the Influence on Drawing Restistance]; Beitr. Tabakforsch. Int. 16 (1994) 11-46. DOI: 10.2478/cttr-2013-0630

14. Gaißer, H.: Die stationäre Strömung in der Cigarette und deren Einfluß auf den Zugwiderstand [Steady State Flow in the Cigarette and its Influence on Pressure Drop]; Beitr. Tabakforsch. Int. 15 (1992) 93-122. DOI: 10.2478/cttr-2013-0626

15. Mitler, H.E. and G.N. Walton: Modeling the Ignition of Soft Furnishings by a Cigarette; U.S. Department of Commerce, National Institute of Standards and Technology, Washington, DC, USA, 1993.

16. Krasny, J.F., W.J. Parker, and V. Babrauskas (Editors): 
Fire Behavior of Upholstered Furniture and Mattresses; William Andrew Publishing, Norwich, NY, USA, 2001. DOI: 10.1016/B978-081551457-2.50001-2

17. Yi, S.-C., E.-S. Song, and M.R. Hajaligol: Mathematical Model of Smoldering Combustion in a Carbonaceous Porous Medium. Part 1 - Development of Pyrolysis and Combustion Models for a Cylindrical Geometry; J. Fire Sci. 19 (2001) 429-448. DOI: 10.1177/ 073490401773732436

18. Hirschler, M.M.: Mathematical Models to Analyse the Effect of Physical Properties of Cigarettes on the Propensity of the Cigarette to Ignite Cellulosic Fabrics; Fire Mater. 21(1997) 33-39. DOI: 10.1002/(SICI)10991018(199701)21:1<33::AID-FAM594>3.0.CO;2-E

19. International Organization of Standardization (ISO): International Standard 287:2009. Paper and Board Determination of Moisture Content of a Lot - OvenDrying Method; ISO, Geneva, Switzerland, 2009.

20. International Organization of Standardization (ISO): International Standard 534:2011. Paper and Board Determination of Thickness, Density and Specific Volume; ISO, Geneva, Switzerland, 2011.

21. International Organization of Standardization (ISO): International Standard 536:2011. Paper and Board Determination of Grammage; ISO, Geneva, Switzerland, 2011.

22. International Organization of Standardization (ISO): International Standard ISO 5636-3:2013. Paper and Board - Determination of Air Permeance (Medium Range) - Part 3: Bendtsen Method; ISO, Geneva, Switzerland, 2013.

23. International Organization of Standardization (ISO): International Standard ISO 8791-2:2013. Paper and Board - Determination of Roughness/Smoothness (Air Leak Methods) - Part 2: Bendtsen Method; ISO, Geneva, Switzerland, 2013.

24. International Organization of Standardization (ISO): International Standard ISO 1716:2010. Reaction to Fire Tests for Products - Determination of the Gross Heat of Combustion (Calorific Value); ISO, Geneva, Switzerland, 2010.

25. Deutsches Institut für Normung (DIN): German Standard DIN 53765:1994. Testing of Plastics and Elastomeres, Thermal Analysis, DSC-Method; DIN, Berlin, Germany, 2010.

26.Zienkiewicz, O.C.: The Finite Element Method in Engineering Science; McGraw-Hill, London, UK, 1971.

27. Wang, M., J. He, J. Yu, and N. Pan: Lattice Boltzmann Modeling of the Effective Thermal Conductivity for Fibrous Materials; Int. J. Therm. Sci. 46 (2007) 848-855. DOI: 10.1016/j.ijthermalsci.2006.11.006

28. Tondini, F., P. Bosetti, and S. Bruschi: Heat Transfer in Hot Stamping of High-Strength Steel Sheets; Proc. Inst. Mech. Eng. B - J. Eng. Manuf. 225 (2011) 1813-1824. DOI: $10.1177 / 0954405411413987$

29. Kashiwagi, T. and H. Nambu: Global Kinetic Constants for Thermal Oxidative Degradation of a Cellulosic Paper; Combust. Flame 88 (1992) 345-368.
30. Fredlund, B.: Modelling of Heat and Mass Transfer in Wood Structures During Fire; Fire Safety J. 20 (1993) 39-69. DOI:10.1016/0379-7112(93)90011-E

31. Kartovaara, I., R. Rajala, M. Luukkala, and K. Sipi: Conduction of Heat in Paper; in: Papermaking Raw Materials, edited by V. Punton, Mech. Eng. Pub. London, UK, 1985, pp. 381-412.

32. Lyman, C.S., T.A. Perfetti, D.M. Riggs, and W.T. Morgan: Thermal Emissivity and Cigarette Coal Temperature During Smolder; Beitr. Tabakforsch. Int. 20 (2003) 381-388. DOI: 10.2478/cttr-2013-0755

33. Baker, R.: Temperature Variation Within a Cigarette Combustion Coal During the Smoking Cycle; High Temp. Sci. 7 (1975) 236-247.

34. Pino, A., J. Pladellorens, J.F. Colom, O. Cusola, and A. Tosas: Using Laser Speckle to Measure the Roughness of Paper; Tappi J. 10 (2011) 7-13.

35. COMSOL, A.B.: COMSOL Multiphysics User's Guide; COMSOL AB, Stockholm, Sweden, 2005.

36 Yeoh, G.H. and K.K. Yuen: Computational Fluid Dynamics in Fire Engineering: Theory, Modelling and Practice; Butterworth-Heinemann, Burlington, MA, USA, 2009.

37. International Organization of Standardization (ISO): International Standard 5660-1:1993. Fire Tests Reaction to Fire - Part 1: Rate of Heat Release From Building Products (Cone Calorimeter method); ISO, Geneva, Switzerland, 1993.

38. Statler Jr, D.L.: A Mechanistic and Modeling Study of Recycled and Virgin Flame Retarded Polycarbonate; Dissertation, West Virginia University, Morgantown, WV, USA, 2008.

39. Baker, R.R. and R.A. Crellin: The Diffusion of Carbon Monoxide Out of Cigarettes; Beitr. Tabakforsch. 9 (1977) 131-140. DOI: 10.2478/cttr-2013-0437

40. Johnsson, J.E. and A. Jensen; Effective Diffusion Coefficients in Coal Chars: Proc. Combust. Inst. 28 (2000) 2353-2359. DOI:10.1016/S0082-0784(00) 80647-5

41. Hesford, M.: A 24 Factorial Experimental Design to Investigate the Influence of LIP Testing Substrate Parameters (Basis Weight, Permeability and Roughness) on LIP Pass Rates and Residual Length Measurements; Abstract ST 49 presented at the CORESTA Meeting Smoke Science/Product Technology Groups, Graz, Austria, 2011.

Corresponding author:

Pablo Guindos, PhD

Fraunhofer Institut für Holzforschung

Bienroder Weg $54 E$

38108 Braunschweig, Germany

E-mail:pablo.guindos@wki.fraunhofer.de 